Saúde pública 



\section{A saúde pública no Brasil}

GILSON CARVALHO

\section{Um pouco de história dos grandes protagonistas do atual sistema de saúde}

A HISTÓRIA dos cuidados com saúde do brasileiro passa, necessariamente, pela filantropia. Mais ainda pelo cunho filantrópico religioso, a caridade. As pessoas eram atendidas pelas instituições e médicos filantropos. Paralelamente a isso, o Estado fazia algumas ações de saúde diante de epidemias, como ações de vacinação e/ou de saneamento básico. Assim ocorreu no final do século XIX e início do XX com o saneamento do Rio de Janeiro e a grande campanha de vacinação contra varíola.

O Estado cuidava também da intervenção em algumas doenças negligenciadas como a doença mental, a hanseníase, a tuberculose e outras. Só mais tarde começa o atendimento às emergências e às internações gerais. A partir de 1923, com a Lei Elói Chaves, a saúde dos trabalhadores atrelada à previdência passa a ser componente de um sistema para os trabalhadores. De início, as caixas de pensão, depois, os institutos e, finalmente, o grande instituto congregador de todos: o INPS.

A história mais recente nos aponta alguns caminhos. O primeiro deles refere-se a um esforço de guerra na extração da borracha e do manganês. Foi criado um sistema de saúde para atender as populações envolvidas. Teve inspiração e financiamento dos Estados Unidos que iniciaram o projeto através de um programa de ajuda. Eram denominados como Serviços Especiais de Saúde Pública (Sesp), mais tarde transformado em Fundação Sesp. Foi o programa mais completo de atenção à saúde associada ao saneamento da história do país. A proposta era ousada. Foi, em quase todos os locais onde se implantou, o único recurso de saúde existente, principalmente nas regiões Norte e Nordeste. A inovação não era só na proposta de intervenção, mas também na gestão de pessoas. Já se trabalhava com uma equipe multidisciplinar dentro da disponibilidade da época. Organizava-se a partir de unidades denominadas mistas onde se fazia o atendimento básico, primeiro atendimento, urgência-emergência e internações hospitalares.

O outro marco foi a $3^{\text {a }}$ Conferência Nacional de Saúde no final de 1963 que coroava vários estudos para a criação de um sistema de saúde. Duas bandeiras dessa conferência: um sistema de saúde para todos (saúde direito de todos os cidadãos) e organizado descentralizadamente (protagonismo do município).

A ditadura militar iniciada em março de 1964 sepultou a proposta poucos meses depois. 
Durante a ditadura, alguns projetos privatizantes como o do Vale Consulta e para as regiões mais pobres uma reedição da Fundação Sesp denominado Programa de Interiorização de Ações e Serviços de Saúde (Piass). O Piass não se implantou por falta de vontade política dos governos à época. Tinha mais virtudes que defeitos. Faltou interesse público para levá-lo à frente.

Nos porões da ditadura gestava-se um sistema de saúde que tinha como objetivo colocar a saúde como direito de todos os cidadãos e um dever consequente do Estado. Essa organização em defesa de um sistema público de saúde com integralidade e universalidade acontecia em pleno regime autoritário, mas sempre na perspectiva de sua superação.

Como conseguir implantar um sistema universal de fazer saúde como os países da Europa iniciaram no pós-guerra dentro da política denominada welfare state? Como conseguir que o Estado brasileiro se responsabilizasse e garantisse esse direito de forma universal?

Entre os vários protagonistas envolvidos nesta luta destacavam-se alguns.

- Movimentos populares - Em primeiro lugar, o cidadão politizado de bairros periféricos, principalmente de São Paulo, e que nenhuma cobertura tinha à saúde e vivia as consequências de ser indigente. Destacam-se nessa luta social do cidadão três grandes protagonistas: os movimentos populares, as associações de bairros e vilas e a Igreja Católica que sofria um choque de povo com a dita preferência pelos mais pobres. Nasciam na Igreja as Comunidades Eclesiais de Base, que também voltadas para o terreno de combate às iniquidades sociais traziam lutas pela justiça, sendo uma das bandeiras o direito à saúde. Essa efervescência começa a buscar por propostas concretas. Algo que não ficasse apenas no discurso ou na simples reivindicação.

- Universidades - Outro protagonista veio das faculdades de medicina com dois momentos inovadores. O primeiro, a necessidade de colocar os estudantes em contato com a realidade local, saindo do apenas ambiente hospitalar. Desenvolveu projetos de integração docente assistencial. O segundo, a transformação dos antigos departamentos de higiene em departamentos de medicina social, mais engajados com a realidade. Esses dois meios começam a gerar profissionais com uma nova visão do Brasil e seu momento. Profissionais comprometidos com o social. Passamos a ter assim um outro protagonista dessa história, os médicos dedicados ao social, muitos deles especializados em saúde pública.

- Partidos políticos progressistas - Na década de 1970 estava o Brasil colocado dentro dos limites do bipartidarismo estrito. De um lado, a Arena, que era considerada o partido dos conservadores guiado pelos militares da ditadura. De outro lado, o MDB histórico, representando a resistência à ditadura, abrigando progressistas ditos de esquerda. $\mathrm{O} \mathrm{MDB}$ abrigava em suas fileiras todos os militantes da esquerda que eram impossibilitados de se constituírem como partidos. Todas as correntes ditas comunistas lá estavam. Os vários grupos se juntaram numa única sigla. O MDB buscava o trabalho junto com a comunida- 
de na periferia dos grandes centros urbanos e em algumas prefeituras. De início conseguiram emplacar alguns deputados, e na segunda investida, no ano 1976, expandiram-se assumindo prefeituras importantes de cidades médias. A grande bandeira: "não seremos prefeituras apenas tocadoras de obras, mas prefeituras voltadas para o social". Nesse social estava a saúde do cidadão que nenhuma cobertura tinha além dos planos de saúde para as empresas de maior porte e o Inamps para cuidar da saúde do trabalhador registrado e de empresas menores que não aderiram a planos de saúde. Depois do MDB, foi a vez de os partidos progressistas se libertarem da sigla emprestada. Além de grupos que aproveitaram siglas anteriores, houve grupos novos que fundaram partidos, como o PT, de corte do coletivo dos trabalhadores. Esses partidos tinham em comum a defesa da saúde juntando população e técnicos da saúde

- Prefeituras com bandeiras progressistas - Ao trio faltava um outro ator. Não acontece isso nem no âmbito federal, nem no estadual, mas no municipal. Os municípios, por estarem mais perto das necessidades da população, carregavam o problema e a angústia do que não se fazia em saúde e prejudicava sua população. Nesse cenário, em 1976, surgiram várias administrações municipais com a proposta de se comprometer com o social e não ser apenas prefeituras tocadoras de obras. Assim se definiu e assim surgiu o que mais tarde se denominou como movimento municipalista de saúde. Sem nenhum dinheiro novo, com o apoio de algumas raras universidades e com uma turma quixotesca de sanitaristas e simpatizantes com a proposta de fazer saúde para toda a população, em especial às camadas sociais mais desfavorecidas. Coincide o tempo com o movimento mundial que culminou na reunião de Alma-Ata e sua declaração com ênfase na atenção primária à saúde. Nascem nos municípios, imitando o que acontecia no mundo, as equipes de atenção primária construída por três profissionais, principalmente: o médico, o enfermeiro e a nova categoria denominada agentes de saúde.

O debate continuava e as experiências e modelos práticos acontecendo Brasil afora. A crise da previdência na década de 1980 provocou que se levasse a cabo uma associação mais forte entre o Inamps e os serviços públicos de saúde. Nasce aí o que se denominou Ações Integradas de Saúde (AIS). O cerne: parceria da previdência com a saúde pública municipal e estadual; prestação de cuidados, principalmente primários ambulatoriais; transferência de recursos da previdência para que fossem realizadas essas ações pelos Estados e municípios. A partir de 1987, as AIS foram aprimoradas com o que se denominou Sistemas Unificados e Descentralizados de Saúde (Suds), que durou até 1991 quando se implantou o Sistema Único de Saúde (SUS).

A discussão de uma proposta inovadora e universal com a comunidade e os técnicos resultou naquilo que se denominou Projeto da Reforma Sanitária. Foi emprestada a Tancredo Neves e apropriada como Proposta de Saúde da Nova República. O movimento foi crescendo e culminou com uma grande assembleia em 1986, que foi a VIII Conferência Nacional de Saúde, em Brasília, com cerca 
de cinco mil pessoas do Brasil inteiro que referendaram a proposta da Reforma Sanitária. Essa presença maciça dos cidadãos usuários foi possível pois as AIS introduziram Conselhos de Saúde, com participação comunitária, em cada município como condição de adesão à proposta.

A proposta da reforma sanitária, referendada pela população, por técnicos gestores foi entregue aos constituintes que absorveram grande parte das teses ao definir a Ordem Social e, dentro dela, a Seguridade Social.

\section{O que ficou definido na legislação}

Ainda que nem tudo fosse absorvido pelos constituintes, os pontos principais assim o foram. Faltou principalmente uma melhor definição da proposta de financiamento do Sistema. A discussão continuou, pois nem todas as questões eram prontamente absorvidas pelos constituintes. O Sistema Único de Saúde nasce num grande acordo entre conservadores e progressistas.

Para entender exatamente o que representa o SUS, analiso a seguir suas definições básicas como saúde direito, seus objetivos, suas funções e seus princípios e diretrizes técnico-assistenciais e gerenciais. A base desta análise é exclusivamente a CF art.193-200 e as Leis 8.080 e 8.142.

\section{SUS como direito do cidadão e dever do Estado}

Como já visto, o Sistema Público de Saúde resultou de décadas de luta de um movimento que se denominou Movimento da Reforma Sanitária. Foi instituído pela Constituição Federal (CF) de 1988 e consolidado pelas Leis 8.080 e 8.142. Esse Sistema foi denominado Sistema Único de Saúde (SUS).

Algumas características desse sistema de saúde, começando pelo mais essencial, dizem respeito à colocação constitucional de que Saúde é Direito do Cidadão e Dever do Estado.

A relevância pública dada à saúde declarada na CF tem o significado do destaque e proeminência da saúde entre tantas outras áreas e setores. Destaque-se que foram consideradas como de relevância pública tanto a saúde pública como a privada. Os juristas entendem nessa relevância pública uma limitação ao simples entendimento de que a saúde seja apenas, pura e simplesmente, um bem de mercado. Os serviços privados de saúde, além de serem de relevância pública, estão subordinados à Regulamentação, Fiscalização e CONTROLE DO SUS. Aí se incluem tanto o sistema privado lucrativo exercido por pessoas físicas ou jurídicas individuais ou coletivas, prestadoras ou proprietárias de planos, seguros, cooperativas e autogestão, quanto o sistema privado não lucrativo, filantrópico ou não. Incluem-se: hospitais, clínicas, consultórios, laboratórios bioquímicos, de imagem e outros, de todas as profissões de saúde e com todas as ações de saúde.

\section{Objetivos do Sistema Único de Saúde}

Lamentavelmente, todas as vezes em que falamos dos objetivos da saúde pensamos em Tratar das Pessoas Doentes. Isso no público e no privado. Esquecemos que o maior objetivo da saúde é impedir que as pessoas adoeçam. 
Conseguimos incluir na CF e na Lei 8.080 outra visão desses objetivos.

$\mathrm{Na}$ CF art.196 consta: "saúde é direito de todos e dever do Estado garantido mediante... o acesso igualitário às ações e serviços para sua promoção, proteção e recuperação".

CF art.198: "atendimento integral com prioridade para as atividades preventivas, sem prejuízo dos serviços assistenciais".

CF art.200: "ao SUS compete, além de outras atribuições no termo da lei... (a listagem de várias ações do SUS)".

A lei que regulamentou a CF foi a 8.080,5 que definiu, bem claramente, os objetivos do SUS: identificar e divulgar os condicionantes e determinantes da saúde; formular a política de saúde para promover os campos econômico e social, para diminuir o risco de agravos à saúde; fazer ações de saúde de promoção, proteção e recuperação integrando ações assistenciais e preventivas.

A saúde deve fazer estudos epidemiológicos sobre os condicionantes e determinantes da saúde; trabalho, salário, comida, casa, meio ambiente, saneamento, educação, lazer, acesso aos bens e serviços essenciais e divulgá-los. Ao não identificar e divulgar as causas das doenças e seus condicionantes e determinantes, passa-se a atribuir à área de saúde a responsabilidade única pela falta de saúde.

Formular a política de saúde de modo a promover, nos campos econômico e social, "o dever do Estado de garantir a saúde consiste na formulação e execução de políticas econômicas e sociais que visem à redução de riscos de doenças e de outros agravos e no estabelecimento de condições que assegurem acesso universal e igualitário às ações e serviços para a sua promoção, proteção e recuperação" (Lei 8.080,2,1). Aqui se identifica o poder dos dirigentes do SUS de atuar na política de saúde, interferindo no campo econômico e social.

Finalmente, o SUS tem que se dedicar às ações de assistência às pessoas por intermédio de ações de promoção, proteção e recuperação da saúde.

Promoção da Saúde, segundo o Glossário do Ministério da Saúde, é “o processo de capacitação da comunidade para atuar na melhoria de sua qualidade de vida e saúde, incluindo uma maior participação no controle deste processo... indivíduos e grupos devem saber identificar aspirações, satisfazer necessidades e modificar favoravelmente o meio ambiente". Mais comumente, dizemos que promover a saúde é trabalhar nas causas do adoecer, com participação efetiva das pessoas como sujeitos e atores de sua própria vida e saúde.

Proteção à saúde é o campo da saúde que trabalha com os riscos de adoecer. As medidas diretas como as vacinas, os exames preventivos, o uso do flúor na água ou associado à escovação etc.

Recuperação da saúde é cuidar daqueles que já estejam doentes ou tenham sido submetidos a todo e qualquer agravo à saúde. É a ação mais evidente dos serviços de saúde. Somos, infelizmente, tendentes a reduzir a ação do setor saúde a essa área. Costumo dizer que quando temos que tratar de doentes ou de acidentados, tenho uma sensação de fracasso dos serviços de saúde e da sociedade por não ter nem conseguido evitá-los. 


\section{Funções do SUS: vegular, fiscalizar, controlar e executar}

\section{- Função de regulação}

Regular alguma coisa é estabelecer as regras para que exista, funcione, consiga os resultados etc. As regras da saúde, na verdade, começam na $\mathrm{CF}$, que estabelece o direito à saúde e as linhas gerais desse direito. Depois vêm as Leis 8.080 e 8.142 que regulamentam melhor esse direito. A partir daí, vão surgindo as regulamentações menores. Na saúde, além de ser necessário regular a organização do sistema público e privado, também se regulamentam as ações e serviços de saúde. Regulação do SUS, de um lado, é estabelecer como devem funcionar os hospitais públicos e privados, as unidades de saúde, os consultórios privados, quem pode exercer a função de médico, dentista etc., quais são os dados essenciais que devem ser gerados pelos serviços; de outro lado, como serão tratadas determinadas doenças de interesse público, quais os medicamentos, quais as dosagens, como será feita a vacinação de adultos, crianças etc., como as pessoas devem entrar no sistema de saúde público para serem atendidas corretamente. Tudo isso e muito mais coisas fazem parte da função de Regulação.

\section{- Função de fiscalização e controle}

Esses dois termos, previstos na CF e na Lei 8.080, se misturam e se completam com outro que é a auditoria. Digo que os termos: Fiscalizar, Controlar e Auditar têm em sua gênese a mesma ferramenta e processo, que é Avaliar. Todos os três termos usam da avaliação que é feita do comparar duas coisas ou duas realidades e emitir um juízo de valor. Avaliar é comparar o que se observa com o que se quer como bom e certo, com um paradigma, um ótimo, uma situação ideal e emitir o juízo de valor se aquilo está do jeito que deveria estar, ou se mais longe ou mais perto do ótimo. Os três termos Fiscalizar, Controlar e Auditar são baseados em avaliação de conformidade. Essa é a grande igualdade entre eles. Entretanto, começam a ser feitas separações entre eles tentando estabelecer diferenças para caracterizar que são processos diferentes. As diferenças podem ser estabelecidas pelo ponto de vista de quem avalia: se de dentro, é controle, se de fora, é fiscalização-auditoria. Não é o de fora da instituição é o de fora do cenário onde acontece, da responsabilidade pelo fazer acontecer. Aí dizem: quem faz deve controlar, e depois nós de fora (de outro departamento, de outro nível, de fora do setor ou da instituição) vamos fiscalizar-auditar. Outros querem separar pelo corte que controle é de processo e que fiscalização-auditoria é de sistema. Aí se misturam e digladiam definidos e definidores. Prefiro ver imensa igualdade entre uma e outra coisa. Apenas vislumbro uma nuance do controle ligado a quem tem a incumbência de garantir que as coisas devam acontecer, e fiscalização-auditoria seja de alguém mais externo e que pode olhar com outro olhar de quem só vai fiscalizar e não tem a incumbência de fazer acontecer.

A fiscalização e controle no SUS pode ser dentro do próprio público ou do privado (contratado-conveniado ou não): da ação de saúde, do serviço, da instituição, dos profissionais, dos contratos-convênios, dos planos e seguros de saúde etc. 
Podemos ainda falar em controle público que é a especificidade de se controlar o público e que se divide em controle público institucional e social. O controle público institucional é aquele exercido pela própria instituição pública, sobre o público. O controle público social é aquele exercido pela sociedade, pelos cidadãos sobre a instituição pública.

\section{- Função de execução no SUS}

O SUS tem que executar, fazer as ações de saúde. É a incumbência do SUS precípua, explicitada em outros locais da CF e da Lei 8.080 e que vamos comentar logo a seguir. Essa execução das ações deve ser feita diretamente ou através de terceiros e também por pessoa física ou jurídica de direito privado. O SUS tem que ter serviços próprios para executar diretamente e tem a possibilidade de contratar terceiros para completar os serviços que não der conta de executar por si próprio. Além disso, a execução de serviços de saúde é livremente permitida ao privado, pessoa física ou jurídica.

Que ações o SUS executa? É interessante, pois o SUS é reconhecido como o Sistema Público de Saúde. Deve, portanto, exercer ações públicas. Antigamente, quando se falava em ações públicas de saúde se pensava na concepção antiga da saúde pública: ações mais coletivas e de promoção e proteção à saúde e para as doenças de maior interesse coletivo e com pouco apelo comercial, como tuberculose, hanseníase, malária, febre amarela, doença mental etc. Hoje, a concepção e o campo da saúde pública, enquanto SUS, é abrangente, incluindo o individual e o coletivo, com ações de promoção, proteção e recuperação da saúde em todos os campos e fazendo todos os campos como vigilância sanitária, epidemiológica, saúde do trabalhador, alimentação e nutrição, saúde da pessoa portadora de deficiência e todos os procedimentos: consultas, exames, urgências, internações, cirurgias, transplantes, UTI etc.

\section{Diretrizes e principios fundamentais do SUS}

As Diretrizes e princípios do Sistema Único de Saúde têm seu fundamento na CF e na Lei 8.080.

Didaticamente, costumo tomar essas diretrizes e princípios unificados e separá-los quanto aos aspectos técnico assistenciais e os técnicos gerenciais que dizem respeito à organização administrativa do sistema.

As diretrizes e principios tecnoassistenciais da CF e Lei 8.080 são: universalidade, igualdade, equidade, integralidade, intersetorialidade, direito à informação, autonomia das pessoas, resolutividade e base epidemiológica.

Universalidade - $\mathrm{O}$ direito à saúde, bem-estar, felicidade é de todos: pobres, ricos; empregados, desempregados; quem tem plano e quem não tem plano... O SUS não pode discriminar quem tem direito: nem discriminação positiva, nem negativa. Universalidade significa o Para Todos.

Igualdade - Não discriminar a prioridade e a qualidade da atenção. Todos os cidadãos têm igualdade de acesso às ações e serviços de saúde. Sem discrimina- 
ção positivo-negativa, com acesso nem tratamento diferenciados para problemas iguais. Essa igualdade, ao não ser praticada, pode virar desigualdade e iniquidade, movida por dois grandes parceiros: o financeiro e o tráfico de influência. O tráfico de influência é um causador da desigualdade de acesso. Muitas vezes queremos reduzir o tráfico de influência, aquele praticado por políticos (vereadores, prefeitos, deputados etc.), mas a maioria dos atos de tráfico de influência é feita diariamente nos serviços de saúde públicos pelos próprios funcionários. É uma quebra da igualdade, quando pessoas têm privilégios por laços de parentesco, favores de autoridades, funcionários etc. Além disso, temos hoje o desafio de criticar a quebra da igualdade da dupla porta de entrada em serviços públicos de saúde que usam de seu poder de influência e da impunidade para fazer uma porta de entrada para os usuários do SUS e outra melhorada e diferenciada para atender os pacientes privados e de planos e seguros de saúde. Os serviços públicos de saúde devem tratar todos de maneira igual sem diferenças odiosas e discriminadoras.

Equidade - Aqui vale comentar sobre a equidade que é a qualificação da igualdade. O princípio da equidade é muitas vezes invocado, mas ele não existe na legislação federal a não ser em algumas legislações, como a do Estado de São Paulo. Equidade é a igualdade adjetivada pela justiça. Pela equidade buscamos tratar diferentemente os diferentes (equidade vertical) e igualmente os iguais (equidade horizontal). No SUS, só se pode fazer equidade e tratar diferentemente a partir das necessidades de saúde. Priorizar atenção e tratamentos só se por carências de saúde. Muitas pessoas imaginam que o SUS possa fazer diferenças a partir do estado de pobreza das pessoas. Pensam que o SUS além de ser dos pobres pode priorizar tratamentos e medicamentos para os chamados carentes. Esse raciocínio é incorreto. Diferenças no SUS só por necessidades de saúde.

Integralidade - A integralidade também pode ser vista sob dois prismas. A integralidade vertical que lembra a necessidade de se ver o ser humano como um todo e não apenas como um somatório de órgãos e aparelhos. O segundo prisma é o da integralidade horizontal onde se entende que a ação deva abranger seus três enfoques: promoção, proteção e recuperação da saúde. Ver como um todo e agir nesse todo, integralmente.

Intersetorialidade - Não pensar saúde só como área de recuperação da saúde: consulta, remédio, especialista, exame, internação... Pensar saúde garantida por políticas econômicas e sociais que diminuam o risco de as pessoas ficarem doentes ou piorarem. Levar em consideração a determinação econômica e social da saúde. Os fatores determinantes e condicionantes da saúde devem sempre ser levados em consideração: "alimentação, moradia, saneamento, meio ambiente, trabalho, renda, educação, transporte, lazer, acesso a bens e serviços essenciais; saúde expressando a organização social e econômica do Brasil" (Lei 8.080,3).

Direito à informação - Todas as pessoas assistidas têm direito a todas as informações sobre seu estado de saúde-doença. Todas as informações sobre os pacientes: exames, prontuários etc. são de propriedade e direito do paciente. $\mathrm{O}$ segredo médico é um segredo consequente do direito primeiro ao segredo que 
é do paciente. Além disso, a população tem direito a "informações quanto ao potencial dos serviços de saúde e de sua utilização pelo usuário".

Autonomia das pessoas - As pessoas - os cidadãos usuários - devem ter preservada sua autonomia na defesa de sua integralidade física e mental. Trata-se da preservação - dentro dos serviços de saúde - da liberdade de decisão dos pacientes. Aqui se completa a autonomia associada ao direito de informação. A verdadeira autonomia é condicionada pelo direito de acesso à informação, o princípio discutido acima. Só bem informado o cidadão poderá usufruir da verdadeira autonomia.

Resolutividade - As ações e serviços de saúde devem atender também ao princípio de ter capacidade de resolução em todos os níveis de assistência. Os serviços de saúde devem buscar resolver os problemas das pessoas da melhor maneira possível e ao menor custo. Essa é uma questão que cada vez fica mais complexa pela incorporação tecnológica cada vez maior e onde o sistema de encaminhamentos acaba por bloquear a capacidade de ser resolutivo. Cada vez mais se resolvem menos problemas que, mesmo os menos complexos, são encaminhados quase que em cadeias. Princípio do SUS: capacidade de resolver problema.

Epidemiologia como base - A epidemiologia é uma das ciências da saúde que têm como objetivo conhecer aquilo que ocorre com a população: as condições ambientais em que vive a população, as condições gerais de saúde, a oferta de ações e serviços de saúde. O objetivo mais importante da epidemiologia é o estudo da morte e de doenças que ocorrem em determinada população, em determinado lugar. A epidemiologia define o perfil demográfico e o perfil de morbimortalidade em relação às doenças agudas e cronicodegenerativas (hipertensão, diabetes, câncer etc.); os agravos dos acidentes de trabalho, de trânsito, de tóxicos, dos homicídios; as doenças evitáveis; as doenças tratáveis precocemente.

As diretrizes e princípios tecnogerenciais da CF e Lei 8.080 são: descentralização, regionalização, hierarquização, gestor único em cada esfera de governo, conjugação de recursos das três esferas de governo, organização dos serviços para evitar duplicidade, complementariedade e suplementariedade do privado, financiamento tripartite e participação da comunidade.

Descentralização - A descentralização no sistema de saúde brasileiro é uma diretriz-princípio. Consta como diretriz na CF e como princípio na Lei 8.080. Descentralização, segundo o Glossário do MS do Projeto de Terminologia da Saúde, é "redistribuição de recursos e responsabilidades entre os entes federados, com base no entendimento de que o nível central, a união, só deve executar aquilo que o nível local, municípios e estados, não podem ou não conseguem. A gestão do SUS passa a ser responsabilidade da União, dos Estados e dos Municípios, agora entendidos como os gestores do SUS". Quem fazia não tem mais a competência de fazer e precisa passar a outra esfera de governo o que fazia e como fazia (se souber ). A descentralização que defendemos é aquela 
com ênfase na municipalização, com regionalização ascendente e gestor único por esfera de governo. Regiões organizadas pelos municípios com a cooperação técnica dos Estados e do MS. É colocar nas mãos do município a decisão do quê e do como fazer saúde e os meios, principalmente o financeiro, para poder fazer. Poder perto da necessidade do povo é mais fácil de o cidadão controlar. Existem entraves a essa descentralização colocados pelo gestor descentralizador. Uns assumem posição favorável com argumentos como descentralizar para desresponsabilizar e colocar menos dinheiro para a saúde deixando para Estados e municípios o ônus. São feitas constantemente acusações de desvio e mau uso dos recursos descentralizados a Estados e municípios. Interpretações restritivas de leis criando controle distorcidos pelos próprios organismos federais, como Tribunal de Contas da União (TCU), Controlaria Geral da União (GCU), Tribunais de Contas dos Estados (TCE) e Sistema Nacional de Auditora (SNA). Desfinanciamento desencadeando desestímulo de se conseguir implantar e implementar o SUS. Muitos servidores descentralizados têm restrições à descentralização (implicitamente sempre temendo maior controle de trabalho, horário e quase nada de ideológico). Existem entraves também por parte dos gestores descentralizados que não querem muitas vezes assumir seu papel e, comodamente, deixam suas competências constitucionais e legais nas mãos dos outros gestores. Outras vezes são limitações por falta de profissionais da área administrativa e técnica, como vigilância epidemiológica, sanitária e ambiental.

Direção única - O SUS é de responsabilidade constitucional das três esferas de governo, não podendo nenhuma delas se eximir dessa obrigação. $O$ comando legal é de que, em cada esfera de governo, só possa ser gestor uma das esferas de governo. No município comanda o prefeito e o secretário municipal de Saúde. No Estado, o governador e seu secretário de Saúde; e na União, o presidente e o ministro da Saúde. A direção única em cada esfera de governo é um complemento da descentralização. Hoje existe uma questão falaciosa sendo discutida. Discute-se que a gestão única é apenas por esfera de governo e não por território. Equivaleria a dizer que na esfera municipal só poderia ter um gestor, não poderiam ser várias secretárias e secretários cuidando da saúde. Apenas um. Entretanto, no território municipal poderia ter um único gestor municipal concomitante a um único gestor estadual ou um único gestor federal. Isso é controverso, e ainda que defendido pelas secretarias estaduais de Saúde, não é reconhecido pelas secretarias municipais de Saúde.

Regionalização - As ações e serviços de saúde devem ser organizados de forma regionalizada. Seria impossível que os 5.600 municípios brasileiros fossem, cada um deles, suficientes e capazes de atender a toda sua demanda em todos os níveis de atenção. A regionalização é fundamental à organização do SUS, mas só dará certo quando for uma regionalização funcional, ascendente, e nunca uma regionalização burocrático-administrativa e descendente. "A proposta de regionalização, sem investimentos para cobrir os 'vazios regionais de infraestrutura', sem redefinir a relação público-privado (especialmente diante dos planos de saú- 
de) e sem mudança nos modelos de atenção, seria mais uma proposta tecnocrática que não daria conta dos desafios atuais do SUS. Sob o pretexto da regionalização, poderia estar havendo um movimento de recentralização de decisões junto ao poder estadual" (Prof. Dr. Jairnilson da Silva Paim - ISC - UFBA.) No mundo inteiro, no público e no privado, sabe-se que ações e serviços de saúde precisam ser organizados de forma regionalizada e hierarquizada. Quer dizer que não se podem alocar todos os serviços em todos os lugares, independentemente de seu tamanho, território e disponibilidade de equipamentos e pessoal. Os serviços de saúde devem se complementar numa associação permanente entre os mais simples e os mais complexos, se referenciando e contrarreferenciando.

Hierarquização - Começa pela atenção ao indivíduo, à família e à comunidade por meio dos Agentes Comunitários de Saúde, do Programa de Saúde da Família, das Unidades Básicas de Saúde com seus procedimentos de menor complexidade tecnológica (equipamentos e aparelhos) e da mais alta complexidade de saber e prática humanos. Da atenção primária se vai à secundária (especialistas, exames mais complexos, internações em clínicas básicas, como pediatria, clínica e cirurgia gerais, ginecologia e obstetrícia). Da secundária à terciária com profissionais e hospitais em áreas mais especializadas. Na quaternária se encontram os profissionais e hospitais superespecializados em uma única área, como os de cardiologia, neurologia, cirurgia plástica etc.

Complementariedade do privado - O art.199 da CF coloca claramente que a saúde está livre à iniciativa privada. Além de ser possível o livre exercício das profissões de saúde e dos serviços privados de saúde, esses poderão também ser utilizados pelo SUS todas as vezes que sua capacidade de atendimento for insuficiente para dar conta da demanda. A complementaridade poderá se dar com o privado através de contrato de direito público ou convênio. Nessa chamada de complementação dos serviços públicos a preferência será dada às entidades filantrópicas e às sem fins lucrativos. Todas as vezes que o próprio estatal não for suficiente para atender a demanda é constitucional recorrer-se complementarmente ao privado. Atenção, que não se trata de entregar o público ao privado (terceirização pelas Organizações Sociais, Organizações da Sociedade Civil de Interesse Público Social (Oscips), Cooperativas, Associações), mas de recorrer ao privado para complementar o público. Não para substituir o público. Ordem de preferência: público estatal, universitário público, universitário filantrópico, filantrópico, privado lucrativo.

Suplementariedade do privado - Na área de saúde, no Brasil, é livre a iniciativa privada que pode ser exercida e utilizada de maneira totalmente liberal, nos consultórios e nas clínicas contra pagamento direto. Pode também ser organizada em forma de operadoras de planos e seguros de saúde, individuais, familiares ou coletivos, conforme faculta a legislação. Entre as operadoras de saúde temos, de um lado, os seguros de saúde, que são seguradoras e não podem ter serviços de saúde; de outro, têm-se as empresas de Medicina de Grupo, o Sistema de Autogestão patrocinado por empresas ou trabalhadores e as Cooperativas Médicas e Odontológicas. 


\section{A política federal de saúde dos últimos 10 anos - 1993-2012}

A decepção é sempre diretamente proporcional ao tamanho da expectativa positiva que se tem. Assim, depois de oito anos de mandato de FHC, as pessoas progressistas estavam prenhes de esperança de que o país mudasse e a saúde pública tomasse os rumos legais.

Muitas foram as discussões e os debates sobre programa de governo para a saúde quando Lula se pôs em caminho. Não foram iluminados que fizeram o programa de governo do Lula, mas centenas de mãos, as mais diversas que tinham um objetivo comum: a construção do SUS constitucional.

Separei alguns desses fatos que podem servir de análise sobre esperança e decepção com o governo Lula e Dilma na área social da saúde.

\section{O PT e sua guinada à diveita neoliberal}

Nem sei se à direita neoliberal, pois os conceitos de esquerda e direita perderam muito de seu sentido. Liberal ou neoliberal é um conceito vivo e já perenizando pelo seu conceito ideológico explícito.

Tenho feito um comentário que recebe críticas acerbas dos petistas inveterados e convictos. Na área de saúde, pois não ouso extrapolar minhas conclusões para outras áreas de que pouco entendo, nenhuma diferença fundamental há entre a proposta dos partidos progressistas com o partido conservador que o precedeu. A mesma lógica mercadológica de usar todos os meios para impor marcas de governo. É o mesmo pensamento neoliberal que glorifica meios e eficiência no atingimento de objetivos. Estão as saídas de gestão pública, induzidas a boca pequena, para serem implementadas na administração de Upas e Samu.

Pensava ser esse um pensamento audacioso e provocador de iras. Foi quando encontrei uma análise do cientista político e professor Luiz Werneck Vianna na revista $P O L I$ (n.25, set.-dez. 2012, p.13-15), porta-voz de instituição do Ministério da Saúde: "Impossível dissociar, em laboratório, as políticas do PT e do PSDB. PT e PSDB são duas colorações da mesma social democracia. São duas faces da mesma identidade política. Não há uma destinação de classe explícita: o PT é o partido dos trabalhadores, dos operários, dos camponeses e o PSDB é o partido dos capitalistas, empresários, dos economicamente privilegiados. Isso não é verdade".

\section{A proposta de Lula e Dilma e a negligência com a saúde}

Uma primeira constatação é em relação à priorização da saúde. Como sempre um discurso de priorização e uma prática pífia. Lula teria confessado em recente bate-papo informal que, infelizmente, pouco tenha feito para a saúde. Lula teve nesses oito anos de governo quatro ministros da Saúde. O primeiro de sua escolha direta, um prócere do partido, mas sem prática de gestão, nem grande conhecedor do SUS. Um segundo, com reconhecido conhecimento de SUS, mas escolhido para um mandato curto e membro de um outro partido da base aliada ao governo. O terceiro, um mandato tampão de um servidor de carreira na saúde, com larga experiência e compromisso com a saúde pública. A 
interinidade impediu que assumisse a revolução do legal. Depois um sanitarista histórico com vasta experiência, mas que não fez a sua equipe, trabalhando com um ministério composto por "vários ministérios" dentro dele, cada um seguindo solo as orientações de seu grupo de indicação e apoio. Sua própria indicação não foi reconhecida como de um partido aliado, ficando na cota do presidente.

Dilma, no primeiro mandato, tem como ministro da Saúde um orgânico do partido, ex-ministro de Lula na área de relações institucionais e que abraçou a saúde com grande entusiasmo e baixo conhecimento de SUS. Um político nato que, segundo veiculado na mídia, está se cacifando para concorrer ao governo de seu Estado. Cercou-se de técnicos de primeira linha, advindos da gestão municipal, mas que, até o momento, não conseguiram levar à frente uma proposta coesa e consistente de política de saúde consolidando o mesmo modelo de prática ilegal. Continuam fazendo o mesmo do mesmo com discurso da eficiência em contraponto com o de falta de recursos. Já transcorreu metade do governo e não se vê nenhuma luz animadora no fim do túnel.

Essa história maniqueísta de contraposição entre financiamento e eficiência se repete a cada novo governo. De um lado, o discurso de necessidade de buscar a eficiência que fará render melhor os recursos atuais. De outro, um discurso de busca de mais financiamento que dizem ser uma proposta descabida, pois mais dinheiro, sem eficiência, levará a mais perda de recursos.

Minha avaliação sobre esses dois polos da discussão é de que as duas questões são fundamentais, indissociáveis nessa área de Saúde Pública. Tenho evidências, de um lado, que me levam a ter certeza de que o financiamento é insuficiente para a saúde pública e, de outro, existe ineficiência. Essa é a pior associação: insuficiência e ineficiência que se potencializam.

\section{O império das portarias inconstitucionais e ilegais}

Dentro da hierarquia da legislação temos, no âmbito federal, a sequência decrescente em peso da legislação. Em primeiro lugar, a preponderância, como lei maior, a Constituição Federal de 1988 alterada por algumas dezenas de emendas constitucionais acontecidas nesses 25 anos. Em seguida, as leis com predominância das Leis Complementares sobre as Leis Ordinárias. Depois, os Decretos Federais. Depois, ainda, as várias portarias provindas dos ministros e das secretarias dos ministérios com predominância daquelas sobre estas. Nada pode ser feito fora dessa hierarquia. Leis, decretos, portarias só podem mandar fazer aquilo que está na Constituição Federal. E assim por diante. As portarias, portanto, hierarquicamente as derradeiras, jamais podem ditar regras que contrariem CF, Leis e Decretos.

Vã expectativa. O que mais ocorre é exatamente o contrário: portarias contrariando frontalmente as leis. São centenas e milhares de portarias ao ano só do Ministro da Saúde e existem ainda outras de seus secretários e o equivalente das agências reguladoras. A grande maioria delas ilegal e/ou inconstitucional. Assim acontece no pós-constitucional como rotina de todos os governos que 
por lá passaram de qualquer matiz ideológico. O único matiz existente é a prepotência de descumprir a lei, pois o Ministério da Saúde acha que é dono do dinheiro que arrecada (única esfera que pode arrecadar) e que se "prejudicará" se cumprir a legislação.

Havia uma esperança explícita de que com o novo governo comandado por Lula a legislação fosse cumprida. O que não ocorreu nestes dez anos: oito de Lula e dois de Dilma.

\section{As marcas de governo e de ministros da Saúde em detrimento da marca SUS}

Primeiro entender que as ilegalidades, em sua maioria, não são praticadas pelo presidente ou por outros ministérios do núcleo duro de governo (Fazenda, Planejamento, Orçamento). É o próprio Ministério da Saúde que cria suas marcas próprias ligadas a cada um dos ministros que por lá passam e que, por vezes, conseguem vender ao presidente. Essa não é uma característica só dos últimos presidentes, mas de quase todos que por lá passaram nas décadas de redemocratização. Exceção seja feita ao governo Collor e seu ministro Alceni Guerra, que fez toda uma campanha para difundir e implantar a marca SUS com normas para fazer e colocar o logotipo em todos os locais de atendimento, em todos os impressos etc. Até bandeira do SUS existia!

Daí para a frente, um festival de marcas que deixam prefeitos e secretários desorientados. Brotam de mentes extremamente profícuas com excesso de retas intenções. Lembrando que todos e cada um dos municípios têm que ler, estudar, entender, explicar para seu prefeito, vereadores, conselheiros, profissionais e até à mídia toda essa parafernália de nomenclatura de vida curtíssima. Para a população, o que importa é a resposta que oferecemos a seus problemas ou depois de acontecidos ou com medidas corretivas antecipatórias. O capricho de cada administração levou a que se inovasse até na nomenclatura brasileira (contratação agora é contratualização) ou se invertessem termos constitucionais (regulação não é mais o conjunto de leis e normas sobre determinado tema, mas a gerência/gestão da oferta de cuidados de saúde). Assim se multiplicam. Entre as marcas de governo que esconderam a marca SUS podemos citar: Nobs, Noas, pacto e seus blocos; redes e entre elas a Rede "Cegonha", nome criticado veementemente pelos movimentos populares da área; farmácia popular e ênfase na faixa de calçada: “Aqui tem farmácia popular” depois desdobrado em "Saúde não tem preço".

Para cada marqueteiro assessorando autoridades há um técnico cheio de saber e de retas intenções, instrumentalizando e ajudando a concretizar o sonho da marca de governo. A ideia mestra hoje no Ministério da Saúde é definir e escolher o legado (marcas) que deixarão para a posteridade!

\section{$O$ imbróglio do financiamento federal para a saúde}

Antes de discussão dos embates do financiamento quero fundamentar a assertiva de que o governo federal vem subfinanciando a saúde e que o Brasil 
gasta recursos insuficientes. A demonstração através de evidência facilitará o entendimento dos equívocos cometidos pelo governo federal nestes últimos dez anos.

Faço o demonstrativo de três evidências a partir de dados concretos mostrando o constante desfinanciamento federal.

$1^{a}$ Evidência: o gasto federal per capita caiu entre 1997 e 2008 e só aumentou depois diante da ameaça da gripe suína. Em 1997 eram R\$ 294 per capita. Em 2003, primeiro ano do governo Lula, R\$ 234, e em 2008, R\$ 289.

2a Evidência: entre 1995 e 2011 caiu o gasto percentual em relação à Receita Federal. Em 1995 o Ministério da Saúde teve disponível para suas atividades $11,72 \%$ da receita corrente bruta da União. Em 2011, esse percentual caiu para $7,3 \%$.

$3^{a}$ Evidência: a participação federal no financiamento da saúde pelas três esferas de governo veio caindo e aumentando a participação de estados e municípios. Em 1980 a participação federal era de 75\%, a estadual, 18\%, e a municipal, de 7\%. Em 1991, 73\% da União, 15\% dos Estados e 12\% dos municípios. Em 2001 a União continua diminuindo seu gasto agora representando 56\%, os Estados, $21 \%$, e os municípios, 23\%. Já em 2011, a União apenas contribuiu com $47 \%$, os Estados, com 26\%, e os municípios, com $28 \%$.

Outro argumento que sempre mostro em meus estudos é sobre o baixo volume de recursos para a saúde pública das três esferas de governo. Faço algumas comparações que acabam sendo evidências do baixo gasto com saúde. Os dados brasileiros são de 2010 e os de outros países, de 2009, obtidos no anuário Estatístico da OMS - Organização Mundial de Saúde.

$1^{a}$ Evidência: podemos comprar os recursos gastos com saúde pública e os gastos per capita dos planos de saúde com seus beneficiários. Os planos de saúde gastariam R\$ 298 bi para atender a toda população brasileira usando o mesmo per capita e sem oferecer todas as ações oferecidas pelo SUS, como as de vigilância, vacinação etc. Se o SUS em 2010 gastou R\$ 138 bi, estariam faltando R\$ 160 bi.

$2^{a}$ Evidência: o gasto médio público como percentual do PIB dos países da OMS foi de 5,5\%. O Brasil tem um gasto de apenas 3,7\%. Se fôssemos usar o mesmo percentual seriam necessários R\$ 210 bi, ou seja, mais R\$ 72 bi dos atuais R\$ 138 gastos.

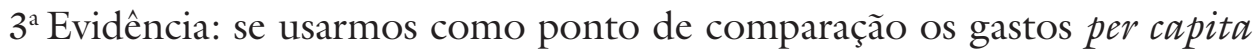
dos países mais ricos do mundo, o Brasil teria necessidade de R\$ 910 bi, ou seja, o sonho inatingível de serem necessários R 772 bi a mais de recursos.

$4^{a}$ Evidência: se usarmos o per capita de países da Europa precisaríamos de R\$ 543 bi, ou seja, R\$ 405 bi a mais que os R\$ 138 bi atuais.

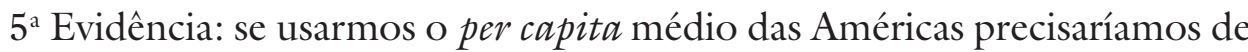
R\$ 538 bi, ou seja, R\$ 400 bi a mais que os atuais R\$ 138 bi. 
Impossível não destacar que o ano de 2003, primeiro do governo Lula, foi aquele em que menos recursos federais foram gastos em saúde, trabalhando-se com um valor per capita. Acima, isso está definitivamente demonstrado: em 1997 eram R\$ 294 por habitante. Em 2003, primeiro ano do governo Lula, caiu ao mínimo patamar, chegando a R\$234, e em 2008, a R\$ 289.

A busca de mais recursos federais para a saúde começa já em 2003 - Projeto de Lei Complementar 01/2003 -, puxada por um deputado médico, histórico do PT, que apresentou uma proposta de regulamentação da EC-29 determinada pela própria EC. Foi um dos projetos mais discutidos e teve um excelente relator, o deputado médico do PT Menezes. Isso se arrastou até 2007.

Em 2007 - primeiro ano do segundo mandato de Lula, deveria ser votada a prorrogação da CPMF. Passou pela Câmara e foi ao Senado. O Senado endureceu, principalmente por ter maioria oposicionista. Fez uma exigência a Lula de que só aprovaria se todos os recursos da CPMF fossem destinados à saúde (cerca de R 40 bi à época). Lula não cedeu por achar que conseguiria a maioria necessária dos votos. Depois de praticamente perdida as chances de aprovação, Lula manda ao Senado um ofício dizendo que os recursos todos seriam aplicados em saúde. A oposição tripudiou depois de tardiamente o presidente ter se colocado de joelhos e votou contra a prorrogação da CPMF. Perdemos todos, pois o projeto de Roberto Gouveia já havia sido votado na Câmara e contando com a permanência da CPMF. Diante disso este projeto enviado ao Senado morreu.

O Senado, também em 2007, apreciou um projeto do senador Tião Viana, médico do PT, destinando 10\% da Receita Corrente Bruta para a saúde. Foi aprovado por unanimidade pelos senadores de oposição e situação. Foi encaminhado à votação da Câmara. O governo, mais que depressa, colocou um relator médico petista, alinhado com o palácio, que apresentou um substitutivo ao do senado. Voltou-se à redação anterior da Câmara e foram retirados os $10 \%$ da Receita Corrente Bruta e criando-se a CPMF (agora CSS) com alíquota menor e destinada só à saúde. No final a Câmara aprovou o substitutivo e derrubou a CPMF (agora CSS). Como houve modificação substantiva na Câmara, o projeto voltou ao Senado. Grande expectativa. No Senado o projeto dele com 10\% da RCB foi aprovado por unanimidade e o da Câmara, exatamente o contrário, e mantendo tudo como antes constante da EC-29. Por ordem expressa da presidente Dilma, o Senado, agora favorável ao governo, votou pelo projeto da Câmara. São momentos que demonstram a distância entre o discurso de privilegiar a saúde e o de asfixiá-la pelo subfinanciamento.

\section{Planos e seguros de saúde subsidiados pelo público}

A última novidade trazida pela mídia são os planos de saúde para os pobres com subsídios do governo, o que equivale a renúncia fiscal. O governo nega oficiosamente, mas o que vaza de notícia é a confirmação de que essa discussão esteja ocorrendo.

As mensagens explícitas (estudos e reuniões desde o final de dezembro e início de 2013): 
- Dilma pessoalmente negocia com seguradoras e administradoras de planos de saúde;

- Pacote: medidas de estímulo financeiro ao setor em troca de melhoras de atendimento;

- Do lado do governo: redução de impostos; linha de financiamento para infraestrutura hospitalar; solução para dívida das Santas Casas;

- Do lado dos planos de saúde: redução de preços para facilitar acesso de pessoas aos planos privados; elevar o padrão de atendimento.

Alguns números interessantes para avaliação da dimensão do Sistema Suplementar de Saúde. Os dados de 2012 consolidados só serão publicados no final de março. Hoje trabalhamos com dados de setembro de 2012. As operadoras de planos médico-odontológicos de saúde somam 1.245. A clientela, a 47,6 milhões. O faturamento global em 2011 foi de 85,5 bi. Estima-se que nos dados consolidados de 2012 chegue perto de 100 bi.

De outro lado, precisamos conhecer os números de gastos tributários (renúncia fiscal) da União com Saúde. Em relação ao imposto de renda, R\$ 13,3 bi (pessoas físicas R \$ 9,9 bi e pessoas jurídicas $\mathrm{R} \$ 3,4$ bi); para medicamentos e produtos químicos e farmacêuticos, R\$ 4,2 bi; e para as filantrópicas, R\$ 2,6 bi. Dois outros programas para oncologia e deficientes têm uma desoneração esperada de mais R\$ 0,8 bi. Para 2013, são da ordem de R\$20,9 bi, segundo dados da Receita Federal.

A renúncia fiscal do imposto de renda está intimamente ligada à desoneração dos planos que pela lógica contábil é cofinanciado por todos os cidadãos. Também a renúncia de medicamentos está estendida a planos e seguros, bem como a das filantrópicas que são beneficiadas pela renúncia e muitas delas oferecem instalações para atendimento de seus próprios planos de saúde como de outros.

A proposta do governo para seguradoras e operadoras oferecerem planos de saúde para os mais pobres tem duas iniquidades intrínsecas. Para os planos, desoneração. Para os pobres, uma sobretaxa, pois além de pagarem ao SUS, obrigatoriamente, pagarão mensalidades onerando sempre as famílias mais numerosas com menor renda per capita.

O governo, abandonando seu papel constitucional de oferecer e garantir um sistema de saúde para todos os cidadãos, faz a maldade completa. Desonera os planos e onera mais os cidadãos.

Pior. Todos sabemos que a história se repetirá: os planos de saúde acolherão preferencialmente os mais jovens (os sem doenças) e rejeitarão os mais velhos (os com doenças). Mais. Como acontece já hoje: farão procedimentos mais simples e baratos e deixarão ao SUS (direito de todos os cidadãos) a execução de procedimentos mais complexos e caros. E se a lei determina ressarcimento continuarão usando de todos os recursos legais para não pagá-lo. É a facilidade da opção esperta de ter lucro sem matéria: recebe por tudo e só oferece parte. 
Uma série de questionamentos se impõe:

Dilma se assessorou de alguém que entenda a Constituição Brasileira e as leis de saúde com a obrigatoriedade de garantia de saúde pública para todos os cidadãos: o tudo para todos (integralidade com universalidade)?

Para melhorar a qualidade do atendimento contratual às pessoas o governo tem que oferecer compensações financeiras?

A questão das Santas Casas e seu déficit crônico na maioria delas, principalmente as de pequeno e médio porte, tem alguma coisa a ver com a renúncia fiscal dos planos ou misturaram-se os canais para gerar compaixão? Grandes e essenciais diferenças: as Santas Casas são parceiras do público e mal remuneradas em preços e prazos. Planos e Seguros estabelecem uma relação comercial lucrativa (lícita pela $\mathrm{CF}$ ) baseada entre outras na lei do direito do consumidor.

Não existe milagre na saúde. A proposta dos governos progressistas dos últimos anos nada mais é que reforçar a proposta neoliberal, usando exatamente o discurso contrário, ao invés de garantir cada vez mais recursos e eficiência ao setor público. Trabalha-se em sentido contrário. A meta é diminuir a universalidade da clientela. Levar as pessoas a cada vez mais se utilizarem de planos privados de saúde pagando sobre o que já pagam. Enfiando a mão no bolso para suprir o que lhes falta e que já está garantido por impostos e contribuições.

Lembrando que depois da liberação de lei sobre planos da época de FHC que autoriza a entrada de capital estrangeiro aconteceu no governo Dilma a primeira transação sem nenhuma tentativa de dificultar o negócio.

\section{Conclusão: reconhecendo os progressos de 10 anos}

É posição comum colocar todas as mazelas do SUS nas costas principalmente dos municípios e as conquistas do SUS na responsabilidade apenas do governo federal, Ministério da Saúde. A autoria de qualquer sucesso deve ser tributada às três esferas de governo, bem como os fracassos da atenção ao cidadão. Estados e municípios são os efetores finais das ações de saúde. Só não aconteceu o pior na saúde pública porque diante do subfinanciamento federal os municípios foram aumentando seus recursos muito acima do piso legal (15\%) chegando a mais de $20 \%$, e os Estados se aproximaram do piso legal de $12 \%$.

Sob o aspecto regulatório temos a comemorar a regulamentação da Lei 8.080 feita através do Decreto 7.508. Um feito de Temporão (ministro de partido aliado) dada continuidade pelo atual ministro Padilha. Com vinte anos de atraso podemos comemorar conquistas.

Outra questão ainda regulatória foi a oficialização por lei da Comissão Intergestores Tripartite (CIT) e Bipartite (CIB). Elas foram criadas por portarias de 1991 e depois de 1993. Seus papéis conflitavam com o do Conselho que tinha respaldo de uma lei. Com a nova lei, que acrescenta artigos na Lei 8.080, aplaina-se esse caminho. 
Muita coisa foi feita e, não obstante, a crítica cerrada ao SUS tenho certeza absoluta de que o sistema público de saúde brasileiro mais faz do que deixa de fazer. Saímos da indigência, do marco zero, para oferecer inúmeros cuidados de saúde individuais e coletivos. De baixa, média e alta complexidade. Preventivos e curativos.

Para se aquilatar o tamanho do SUS é necessário conhecer os números de 2012. O total de procedimentos das três esferas de governo chegou ao astronômico número de 3,9 bi. Só de internações, $11 \mathrm{mi}$, sendo 3,3 mi de cirurgias, 2 mi de obstetrícia e $6 \mathrm{mi}$ de internações clínicas. Exames, $887 \mathrm{mi}$, incluindo os bioquímicos e os de imagem. Ações de promoção e prevenção, 583 mi. A sensação exata é de que muito foi feito, mas ainda se tem para fazer. Na verdade, mais foi feito do que resta fazer.

Ainda em relação a novos desafios rememoro aqui os 13 compromissos da Dilma em campanha presidencial. Cada um desses itens tem compromissos internos onde a maioria não saiu do papel.

Treze pontos que vão melhorar a saúde dos brasileiros e fortalecer o SUS no governo Dilma (programa acordado com os partidos políticos da base). de doenças.

1) Incrementar as ações de proteção e promoção da saúde e prevenção

2) Ampliar o acesso da população às ações e serviços de saúde.

3) Humanização, acolhimento e qualidade.

4) Avançar na política de assistência farmacêutica com distribuição gratuita de medicamentos e fortalecer o programa farmácia popular implantada pelo governo Lula.

5 ) Fortalecer a saúde mental e promover o tratamento do uso abusivo do álcool, do crack e de outras drogas.

6) Garantir financiamento para investimento na melhoria da infraestrutura da rede de atenção à saúde do SUS.

7) Aprofundar as políticas de gestão do trabalho e a educação na saúde.

8) Ampliar a qualidade de gestão do SUS modernizando os seus mecanismos de gestão.

9) Financiamento crescente e estável para o setor, compatível com o crescimento, o desenvolvimento econômico e social do país e com as necessidades do SUS.

10) Aprovar a lei de responsabilidade sanitária.

11) Fortalecer o controle social com gestão democrática e participativa.

12) Aumentar a capacidade de regulação do estado brasileiro sobre os diversos setores econômicos que influenciam a saúde.

13) Ampliar as políticas de fortalecimento e desenvolvimento do complexo produtivo da saúde. 


\section{Referências}

Brasil - Legislação: CF; Leis 8.080 e 8.142; LC 141. Disponível em: <http://www. senado.gov.br>.

Brasil - Dados. Disponível em: <http://www.datasus.gov.br>.

RESUMO - O artigo apresenta uma análise retrospectiva dos últimos dez anos de governo federal e da saúde pública no Brasil. Inicialmente trabalha a história da construção do Sistema Único de Saúde (SUS) e seus principais protagonistas. Depois analisa o SUS, seus objetivos, funções, diretrizes e princípios. Finalmente, faz a análise do governo progressista brasileiro dos dez últimos anos em relação à saúde. Conclui pelo descumprimento contumaz da legislação e das diretrizes por que sempre propugnou em relação à saúde.

PALAVRAS-CHAVE: Saúde pública, Administração pública, Sistema Único de Saúde (SUS), Governo federal, Ministério da Saúde.

ABSTRACT - The essay provides a retrospective analysis of the last ten years of the Federal Government and of Public Health in Brazil. It initially expounds the history of how the Brazil's Public Health System was built - the SUS [Unified Health System] and its main players. It then analyzes the SUS, its goals, functions, policies and principles. Finally, it examines Brazil's progressive government over the last ten years with regard to health care. And concludes with the contumacious noncompliance of the legislation and public policies that have always advocated health care.

KEXWORDS: Public health, Public administration, Unified Health System (SUS), Federal government, Ministry of Health

Gilson Carvalho é médico pediatra, especialista em saúde pública e administração hospitalar, mestre e doutor em saúde pública pela Faculdade de Saúde Pública da USP. Foi secretário de Saúde de São José dos Campos (SP) e secretário de Assistência à Saúde do Ministério da Saúde (DF). É autor do livro Participação da comunidade na saúde, editado, para distribuição gratuita, pelo Centro de Educação e Assessoramento Popular de Passo Fundo (RS). @ - carvalhogilson@uol.com.br

Recebido em 2.4.2013 e aceito em 18.4.2013. 